Louisiana State University

LSU Digital Commons

Faculty Publications

Department of Biological Sciences

$1-1-2015$

\title{
Hurricane wrack generates landscape-level heterogeneity in coastal pine savanna
}

\author{
William J. Platt \\ Louisiana State University \\ Dwayne Joseph \\ Grambling State University \\ Darin P. Ellair \\ Louisiana State University
}

Follow this and additional works at: https://digitalcommons.Isu.edu/biosci_pubs

\section{Recommended Citation}

Platt, W., Joseph, D., \& Ellair, D. (2015). Hurricane wrack generates landscape-level heterogeneity in coastal pine savanna. Ecography, 38 (1), 63-73. https://doi.org/10.1111/ecog.00731

This Article is brought to you for free and open access by the Department of Biological Sciences at LSU Digital Commons. It has been accepted for inclusion in Faculty Publications by an authorized administrator of LSU Digital Commons. For more information, please contact ir@lsu.edu. 


\title{
Hurricane wrack generates landscape-level heterogeneity in coastal pine savanna
}

\author{
William J. Platt, Dwayne Joseph and Darin P. Ellair
}

W. J. Platt (btplat@lsu.edu) and D. P. Ellair, Dept of Biological Sciences, Louisiana State Univ., Baton Rouge, LA 70803, USA. - D. Joseph, Dept of Biology, Grambling State Univ., Grambling, LA 71245, USA. DJ also at: Dept of Plant and Environmental Science, Clemson Univ., Clemson, SC 29631, USA.

\begin{abstract}
Wrack (vegetation debris) deposited by storm surges of major hurricanes along the northern Gulf of Mexico produces depressant effects that vary from partial to complete mortality of groundcover vegetation in coastal savannas. As wrack decomposes or is relocated by a subsequent hurricane, patches are opened to colonization. We postulated that patterns of wrack deposition and removal, coupled with differential responses by savanna plant species should produce alternate states of groundcover vegetation. We explored extreme effects of wrack deposited by Hurricane Katrina (2005) in savannas dominated by slash pine Pinus elliottii and cordgrass Spartina patens and located above mean high tide at the Grand Bay National Estuarine Research Reserve, Mississippi, USA. In 2008, we established plots in adjacent areas with and without wrack deposits. Almost no groundcover plant species occurred in wrack deposits compared to adjacent groundcover without wrack. We simulated redistribution of wrack during a new storm surge by removing wrack from replicated plots and depositing it in plots without wrack, recording plant species in treatment and control plots before, then one month and one year after manipulations. One year later, about half the species present before wrack addition (especially dominant graminoids) grew back through redistributed wrack, suggesting that some species were resistant to burial of limited amounts of wrack. Wrack removal resulted in germination and establishment of numerous herbaceous plant species not in undisturbed groundcover, doubling total aboveground numbers of species in the pine savanna and shifting groundcover communities to alternate states not present prior to Katrina. Removal of wrack opens space colonized by resilient species, including those transported in wrack and those surviving intervals between disturbances belowground. Wrack dynamics (deposition and removal) generated alternate states that resulted from resistance- and resilience-driven changes in different patches of groundcover in coastal savannas.
\end{abstract}

Tropical cyclones are prominent large-scale disturbances of coastal ecosystems. During landfall, storm surges affect coastlines, especially those with shallow elevation gradients. For example, Hurricane Katrina storm surges extended as much as $20 \mathrm{~km}$ inland along the Gulf coast of Mississippi (FEMA 2005, Knabb et al. 2005), and some coastal areas were inundated by $>5 \mathrm{~m}$ of ocean water (Fritz et al. 2008). Flooding associated with storm surges potentially changes sediments, introduces saline water, and deposits debris, or wrack (Emanuel 2005). Such effects, especially those produced by major hurricanes, disrupt coastal ecosystems, and potentially produce shifts to alternate states (Davis et al. 2004, Lam et al. 2011). Such disturbances are likely worldwide in those areas where hurricanes make landfall.

Deposition of large amounts of wrack in coastal ecosystems often occurs when major hurricanes approach coastlines along the Gulf of Mexico. Massive wrack mats consisting of fragments of herbaceous plants (mostly grass and sedge stems from coastal marshes) and floating wood are pushed ashore (Hackney and Bishop 1979). Diverse items associated with humans (plastic bottles, aluminum cans, household items, etc.) also have become pervasive in wrack generated by recent hurricanes (unpubl.). During landfalls, wrack mats are transported inland, often to elevations well above normal tidal influence. As the storm surge moves inland and retreats, deposition of wrack occurs inland at distances dependent on the extent and height of storm surges, local topography and resulting currents, and obstacles such as vegetation that trap the wrack (Bush et al. 1996).

Post-hurricane observations suggest three main effects of wrack deposits. These include: 1) vegetation and soil is buried beneath dense mats of dead vegetation, 2) salinity of the soil is increased because wrack transported across ocean waters becomes saturated with saltwater, and 3) massive carbon deposits added to the substrate do not decompose rapidly (Roman et al. 1994, Guntenspergen et al. 1995, Bush et al. 1996). Thus, wrack deposited during major tropical cyclones, especially when above tidal influence, may produce large, extended effects. These effects potentially could result in marked changes in vegetation (sensu Platt and Connell 2003, del Moral and Lacher 2005), the most 
extreme of which might generate alternate states (sensu Scheffer et al. 2001, Scheffer and Carpenter 2003).

We studied effects of wrack deposits on groundcover plant communities in coastal slash pine-cordgrass savannas. At the Grand Bay National Estuarine Research Reserve (GBNERR) in southeastern Mississippi, USA, pine islands located $15-30 \mathrm{~cm}$ above sea level and imbedded in coastal marshes 5-6 km from the Gulf of Mexico were inundated by a $\sim 5 \mathrm{~m}$ storm surge during landfall of Hurricane Katrina (FEMA 2005). Large bands of wrack, often 20-40 m wide and 1-2 $\mathrm{m}$ deep, were deposited in these savannas (FEMA 2005, Rodgers et al. 2009, Tate and Battaglia 2013). Groundcover vegetation was buried and killed. Although wrack deposits became compacted over time, dense mats still covered the ground surface several years later, and few plants had colonized wrack deposits. In contrast, species of plants in surrounding savanna not buried by wrack, although top-killed by the storm surge, regrew from belowground structures (rhizomes and roots) and reestablished groundcover characteristic of coastal pine savannas.

We developed our study based on post-Katrina field observations. In 2008, almost three years after Katrina landfall, we quantitatively described debris and groundcover plant communities in adjacent areas with and without wrack deposits. Those data were used to design an experiment to explore changes that might occur if a second tropical cyclone were to generate a storm surge that shifted the remaining wrack into areas without wrack deposits, concurrently opening the ground surface in areas with wrack. We anticipated that deposition of wrack should differentially depress species in the intact groundcover, depending on their ability to regrow through deposited wrack, and that removal of wrack from deposits should facilitate germination and establishment of species of plants with seeds beneath wrack. Building on life history differences in responses of trees to hurricanes (Bellingham et al. 1995, Batista and Platt 2003), we further hypothesized that savanna plant species might exhibit differential resistance (ability to survive burial by wrack) and resilience (ability to respond after the wrack was removed). We anticipated that if these groups were different, then hurricane wrack dynamics could result in alternate savanna groundcover communities occurring in patches that had and had not contained wrack deposits. We used the results of our field experiment to explore concepts of disturbanceinduced changes in the composition and dynamics of the groundcover of coastal savannas.

\section{Methods}

\section{Study site}

We conducted our study at the Grand Bay National Estuarine Research Reserve (hereafter, GBNERR), Jackson County, Mississippi. The GBNERR $\left(30^{\circ} 24^{\prime} \mathrm{N} ; 88^{\circ} 24^{\prime} \mathrm{W}\right)$ is a 7284 ha marine protected area comprised of the Grand Bay National Wildlife Refuge and the Grand Bay Savanna Coastal Preserve (Hilbert 2006). Coastal pine savannas at the GBNERR and along the Mississippi coast occur on 'pine islands' of fine sands elevated above surrounding longhydroperiod marshes (Harper 1914). These are relict sand bars that extend parallel to Bayou Heron, the main drainage system, about 5-6 km inland from the coastline. Pinus elliottii (slash pine) dominates the overstory. The groundcover, dominated by Spartina patens (cordgrass), contains primarily perennial life forms: graminoids (e.g. Panicum virgatum, Andropogon virginicus, Rhynchospora sp., Dichanthelium sp.), forbs (e.g. Solidago sempervirens, Eupatorium leucolepis, Scutellaria integrifolia, Polygonum sp.), shrubs (e.g. Morella cerifera, Baccharis halimifolia, Ilex vomitoria), and lianas (e.g. Toxicodendron radicans, Rubus trivialis, Ipomoea sagittata).

Hurricane Katrina made landfall along the Mississippi coast about $100 \mathrm{~km}$ west of the GBNERR on 29 August, 2005. The storm surge inundated the entire GBNERR; estimates of maximum storm surge depths in coastal pine savannas were 5-6 m (FEMA 2005). Bands of wrack, often several hundred meters long, were deposited roughly parallel to the coastline in pine savannas as the storm surge floodwaters receded after the hurricane made landfall. These deposits tended to occur as large, somewhat discrete patches at roughly similar elevations $(20-30 \mathrm{~cm}$ above the marshes) along the 'crests' of islands and often were 1-2 m deep and 10-40 m wide (Platt unpubl.). Most species of groundcover plants did not recover from burial by wrack. Although wrack had become compacted by 2008, few plants had germinated and grown through the wrack. As a result, large patches of wrack with little vegetation present were located among trees and shrubs that survived the hurricane.

\section{Initial field study}

We selected a large, accessible pine savanna island for study in June 2008. This island, located $5.6 \mathrm{~km}$ inland from the Gulf of Mexico and surrounded by lower swales with fresh and brackish marshes, was approximately $1 \times 0.25 \mathrm{~km}$ and oriented in a roughly northwest-southeast direction, paralleling Bayou Heron. We conducted a survey of the island and located eight areas, each containing large continuous bands of wrack that had not been disturbed by humans (who drove across the deposits in large trucks when salvaging artifacts of human origin transported in the wrack). We randomly selected three of these areas to use for study. These areas, each $0.08-0.12$ ha, were irregular in shape, and separated by about 100-200 m; we considered these blocks in our field design to account for local variation among areas with wrack deposits. Locations of these blocks ranged from $30^{\circ} 24.60^{\prime}$ to $30^{\circ} 24.69^{\prime} \mathrm{N}$ and $88^{\circ} 24.81^{\prime}$ to $88^{\circ} 25.05^{\prime} \mathrm{W}$. Each block contained a discrete Katrina wrack deposit and an adjacent area without Katrina wrack.

Vegetation debris comprising wrack deposits and litter in vegetation without wrack deposits were described in 2008. We established two transects in each block, one across and perpendicular to the long axis of the wrack deposit and the other in a similar direction and distance across nonwrack vegetation. Lengths of transects depended on the width of the wrack deposit $(10-40 \mathrm{~m})$. At $2 \mathrm{~m}$ intervals along transects we measured depth of organic debris/litter. In addition, we measured number and diameter of wood 
pieces (logs, branches) in $2 \mathrm{~m}$ segments ( $1 \mathrm{~m}$ wide) along transects. Data were used to describe the size distribution of wood pieces and compare numbers of pieces of wood and depths of wrack/litter in areas with and without wrack.

We established 16 plots of $4 \mathrm{~m}^{2}$ in each block. Eight were located in wrack and eight in vegetation with no wrack. Plots were randomly located, with the restriction they were separated by at least $5 \mathrm{~m}$ and were at least $2 \mathrm{~m}$ from edges of wrack bands (the edges sometimes were indistinct three years after Katrina). A total of 48 plots were used in this study. A $1 \mathrm{~m}^{2}$ quadrat in the center of each plot (surrounded by at least a $0.5 \mathrm{~m}$ buffer that was maintained as undisturbed wrack or no wrack) was marked using rebar, PVC and a metal tag with a unique number. We used an Aquaterr EC 300 salinity meter to measure soil salinity adjacent to each wrack and non-wrack plot at a depth of approximately $5-10 \mathrm{~cm}$, similar to measurements we had previously made in a number of coastal pine savannas examined within a few months after Hurricane Katrina landfall. We mapped latitude and longitude and obtained relative elevations of plots using a Topcon rotating laser RL-H to ensure that wrack and non-wrack plots were at similar elevations. We sampled wrack/litter adjacent to each plot and species composition of plots in 2008. Wrack/litter in a $20 \times 20 \mathrm{~cm}$ area was collected, transported to the lab, dried for three days in a drying oven at $70^{\circ} \mathrm{C}$, and then weighed. The wrack/litter was then separated into 3 components (pine needles, wood pieces, and wrack/litter - fine decomposing material) and weighed. Species of plants in each plot were recorded in June, 2008, prior to treatments.

We conducted three different analyses of pre-treatment data. First, we analysed dry weight mass of the three components in wrack/litter deposits adjacent to plots (natural log transformation of wood and wrack/litter and square root of pine needles to increase normality) and pre-treatment species numbers (natural $\log$ transformation of $\mathrm{n}+1$ to eliminate zero values) in plots as a randomized block design ANOVA conducted using Proc Mixed in SAS 9.3 software (SAS Inst.). In these analyses, blocks were considered random effects, and presence/absence of wrack was considered a fixed effect. For all analyses, denominator degrees of freedom were calculated using the Kenward-Roger method (Kenward and Roger 2009). Second, multiple regression was used to explore relationships between pretreatment numbers of species and components of wrack (wood, wrack/litter, and pine needles). Wrack and non-wrack patches were analyzed separately using Proc Reg in SAS 9.3. Residuals were checked for normality; one outlier was removed from analysis of nonwrack patches. Third, we conducted a non-metric, multidimensional scaling (NMS) ordination using SAS 9.3 to explore differences in species assemblages in wrack and nonwrack plots. We used Proc Distance to generate matrices of Jaccard dissimilarities using presence/absence of species in plots prior to treatments, then used Proc MDS to perform the ordinations using those matrices. Three dimensional ordinations were used to lower badness-of-fit to $<0.2$.

\section{Experimental wrack manipulation}

We conducted an experiment in which we simulated effects of a subsequent hurricane on wrack deposits and the groundcover vegetation. We removed wrack from four randomly selected wrack plots within each block. All wrack within the central $1 \mathrm{~m}^{2}$ quadrat was removed by clipping along the edges and then carefully picked up using a pitch fork and rake so as not to disturb underlying soil or the surrounding buffer area. This procedure resulted in some wrack particles less than $2 \mathrm{~cm}$ in length remaining as a fine layer of debris on undisturbed soil. Wrack removed from the plot was placed on an adjacent tarp, and once all wrack from the plot was on the tarp, it was transported to a randomly selected non-wrack plot within the same block. This transported wrack was spread as evenly as possible over the central $1 \mathrm{~m}^{2}$ of the non-wrack plot. The other eight plots ( 4 wrack plots and 4 non-wrack plots) were left without disturbance to serve as controls.

We sampled plots for vegetation three times: prior to any treatment (June, 2008), after one month (July, 2008) and after one year (June, 2009). Subsequently, all plots were rechecked annually until 2012 to determine if composition had changed with respect to recolonization of dominant savanna graminoid species. We recorded numbers of plant species of four life forms (graminoids, forbs, shrubs, lianas) in treated and non treated plots at each census. Identifications were made using Weakley (2012) and USDA, NRCS (2013). Vouchers were deposited in the LSU herbarium. A list of 77 plant species recorded in plots during this study and their designated life form (27 graminoids, 29 forbs, 11 shrubs, and 10 lianas) is presented in Supplementary material Appendix 1.

We conducted analyses of post-treatment data using total numbers of species and numbers of each life form. Data ( $n+1$ to eliminate zero values) were natural log transformed and analysed as randomized block design ANOVAs with repeated measures, using Proc Mixed in SAS 9.3 software (SAS Inst.). For all analyses, denominator degrees of freedom were calculated using the KenwardRoger method (Kenward and Roger 2009). We conducted two separate analyses comparing numbers of species over time: 1) in plots that had wrack and from which wrack was or was not removed, and 2) in plots that did not have wrack, and to which wrack was or was not added. For each analysis, we compared total numbers of species and the different life forms prior to treatment and at one and 12 months after treatment using t-tests with Tukey-Cramer adjustments. We also conducted two non-metric, multidimensional scaling (NMS) ordinations using SAS 9.3 to compare species assemblages one year after treatment in treated/untreated wrack plots and in treated/untreated non-wrack plots. We used Proc Distance to generate matrices of Jaccard dissimilarities using presence/absence of species, and then used Proc MDS to perform the ordinations using those matrices. Three dimensional ordinations were used to lower badness-of-fit to $<0.2$.

\section{Results}

\section{Initial field study}

Substantial wrack deposits were present in pine savannas at the GBNERR in 2008. These deposits consisted of herbaceous marsh vegetation intermixed with pieces of wood and 
various human artifacts. Although wrack had decomposed to some extent, dense compact mats covered large areas three years following Hurricane Katrina. Depth of wrack $(13.0 \pm 3.6 \mathrm{~cm}$ [mean \pm one standard error here and afterwards]) was much greater than the depth of litter $(1.0 \pm 0.13 \mathrm{~cm})$ in adjacent pine savannas without wrack deposits. More wood was present in wrack deposits (20.1 \pm 4.2 pieces $\left.2 \mathrm{~m}^{-2}\right)$ compared to adjacent areas without wrack $\left(8.9 \pm 1.6\right.$ pieces $\left.2 \mathrm{~m}^{-2}\right)$. Both wrack and non-wrack plots contained a range of sizes of wood, from small branches and stems of shrubs ( $<2 \mathrm{~cm}$ in diameter) to fallen trees $20-30 \mathrm{~cm}$ in diameter. Most wood was in the smallest size classes $(0-2 \mathrm{~cm})$, both in areas with wrack $(67 \pm 7 \%)$ and without wrack $(64 \pm 5 \%)$.

The mass of dead plant material in wrack was almost six times the mass in litter in adjacent non-wrack areas. The mass of both wrack/litter and wood was much greater for wrack areas than non-wrack areas (Fig. 1); ANOVA indicated significant differences (wrack/litter: $F_{1,2}=119.08$; $\mathrm{p}=0.008$; wood: $\left.\mathrm{F}_{1,44}=7.45 ; \mathrm{p}=0.009\right)$. In contrast, similar amounts $\left(\mathrm{F}_{1,44}=0.07 ; \mathrm{p}=0.793\right)$ of pine needles, which reflected deposition from overstory trees since the hurricane, were present in both areas (Fig. 1). The wrack contained densely packed fragments of culms of marsh grasses and rushes $\left(0.3-0.6 \mathrm{~g} \mathrm{~cm}^{-3}\right.$ dry weight, on average), which reduced air space in wrack and resulted in a densely packed layer over the soil surface several years after deposition.

Soil salinities changed over the three years following Hurricane Katrina. Shortly after Katrina, elevated salinity (4-9 ppt) occurred in soil beneath wrack and in soil of pine savannas we examined that had been inundated for several days by the storm surge. Three years after Hurricane Katrina, soil salinity was lower and did not differ in plots with and without wrack. Salinity averaged $1.5 \pm 0.1 \mathrm{ppt}$ in plots with wrack and $1.6 \pm 0.1 \mathrm{ppt}$ in plots without wrack.

Wrack burial during Katrina decreased numbers of plant species in coastal pine savanna groundcover. In June, 2008, prior to experimental manipulations, on average there were 0.85 ( $\pm 1 \mathrm{SE}$ ranged from $0.65-1.09$ ) plant species $\mathrm{m}^{-2}$ in wrack plots, compared to 8.44 ( $\pm 1 \mathrm{SE}$ ranged from 7.40-9.61) plant species $\mathrm{m}^{-2}$ in non-wrack plots $\left(F_{1,4.07}=95.11 ; \mathrm{p}<0.001\right)$. Species richness was not

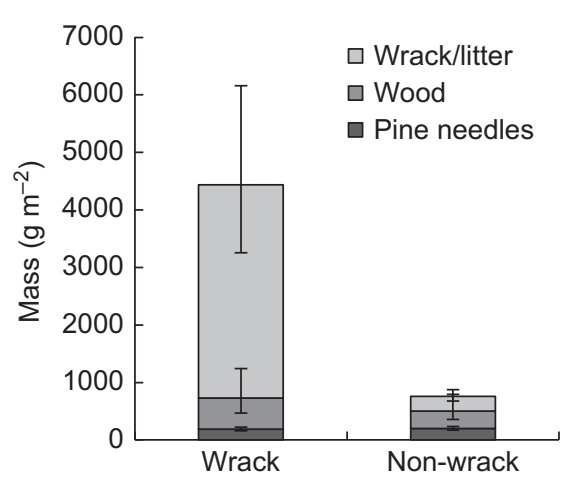

Figure 1. Composition of wrack deposits and litter in surrounding coastal pine savanna at the Grand Bay National Estuarine Research Reserve in 2008, three years after Hurricane Katrina. Values are back-transformed means; vertical bars denote standard errors. related, however, to the mass of wrack $\left(\mathrm{F}_{3,20}=0.14\right.$; $\mathrm{p}=0.937)$ or the mass of litter $\left(\mathrm{F}_{3,19}=0.29 ; \mathrm{p}=0.834\right)$. Field observation indicated that microsites with little wrack or litter (e.g. shrub shadows that blocked deposition of substantial debris) often contained plants, resulting in species numbers independent of total wrack or litter in a plot.

Species composition differed among plots with and without wrack. The three-dimensional NMS ordination (badness-of-fit $=0.12$ ) indicated separation of wrack and non-wrack plots along Axis 1 (Fig. 2). Wrack plots in different blocks also were separated along Axis 2 (Fig. 2). Species in wrack plots constituted a subset of species in non-wrack plots; only 1 of the 9 species recorded in wrack plots did not occur in any non-wrack plot. Most shared species were shrubs or lianas, but different species occurred in wrack plots in different blocks.

\section{Experimental wrack manipulation}

\section{Numbers of species}

Removal of wrack resulted in large increases in total numbers of groundcover species (Fig. 3a). Overall, ANOVA indicated a significant effect of wrack removal $\left(\mathrm{F}_{1,1.69}=33.4\right.$, $\mathrm{p}=0.041)$, time since removal $\left(\mathrm{F}_{2,21}=47.39, \mathrm{p}<0.001\right)$, and a significant interaction between wrack removal and time since removal $\left(\mathrm{F}_{2,21}=7.18, \mathrm{p}=0.004\right)$. Mean numbers increased from 1.7 ( $\pm 1 \mathrm{SE}$ ranged from 1.3 to 2.2 ) to 3.9 ( $\pm 1 \mathrm{SE}$ ranged from 3.3 to 4.7 ) species $\mathrm{m}^{-2}$ during the month following removal and to $13.4( \pm 1 \mathrm{SE}$ ranged from 11.4 to 15.7$)$ species $\mathrm{m}^{-2} 12$ months after removal. Removal of wrack thus resulted in significant increases in species richness at both one month $\left(\mathrm{t}_{1,22}=-5.51 ; \mathrm{p}<0.001\right)$ and 12 months $\left(\mathrm{t}_{1,22}=-9.59 ; \mathrm{p}<0.001\right)$ following wrack removal. In contrast, in plots with wrack not removed, mean numbers of species did not change greatly over time, producing the significant overall interaction between treatment and time. Mean numbers of species $\mathrm{m}^{-2}$ in June and July, 2008, were 0.7 ( \pm 1 SE ranged from 0.4 to 1.0 ) and 1.0 ( \pm 1 SE ranged from 0.8 to 1.4 ), and 12 months later were 2.4 ( $\pm 1 \mathrm{SE}$ ranged from 2.0 to 3.0). Numbers of species $\mathrm{m}^{-2}$ in wrack plots thus did not increase significantly $\left(\mathrm{t}_{1,22}=-1.78 ; \mathrm{p}=0.498\right)$ in the first month,

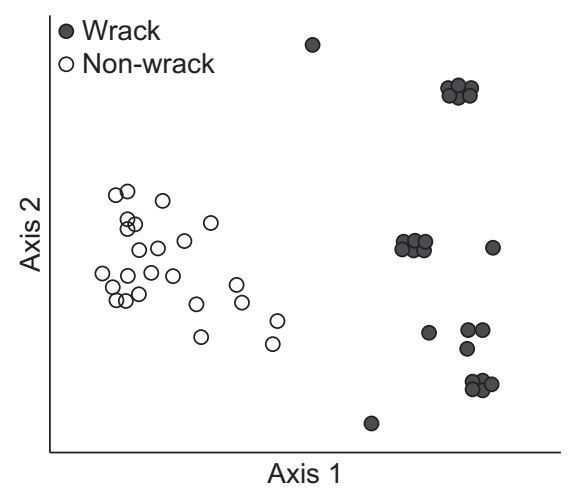

Figure 2. NMS ordination depicting pre-treatment species assemblages. Closed circles denote wrack present; open circles denote no wrack present. Axes 1 and 2 only of the threedimensional ordinal space are shown for clarity. 
(a) Wrack

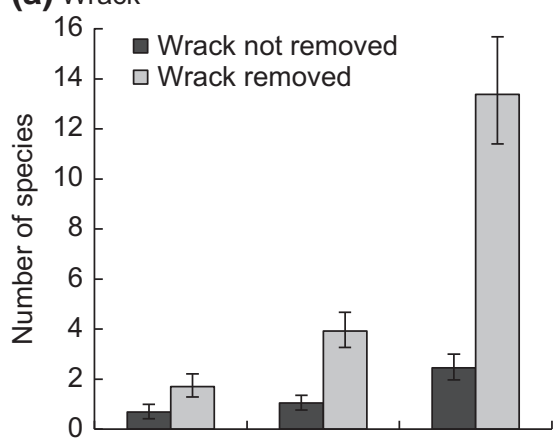

(b) Non-wrack

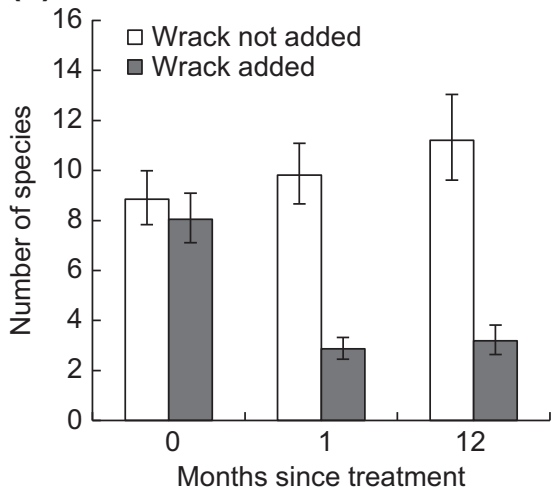

Figure 3. Effects of removal of wrack from wrack plots (a) and addition of wrack to non-wrack plots (b) on species richness. Back-transformed means and standard errors (vertical bars) are presented for treatments and controls (no manipulation) at each of three sampling times: 0,1 , and 12 months after treatment. but did increase slightly 12 months later $\left(t_{1,22}=-4.11\right.$; $\mathrm{p}=0.006)$. Differences between plots with wrack present and removed were significant $1\left(\mathrm{t}_{1,2.26}=-4.92 ; \mathrm{p}<0.001\right)$ and 12 months $\left(\mathrm{t}_{1,3.77}=-7.62 ; \mathrm{p}<0.001\right)$ after treatment.

Addition of wrack in June, 2008, resulted in decreases in total numbers of groundcover species (Fig. 3b). There were significant overall effects of wrack addition $\left(F_{1,18.5}=65.75\right.$, $\mathrm{p}<0.001)$, time since addition $\left(\mathrm{F}_{2,21}=47.25, \mathrm{p}<0.001\right)$, and an interaction between wrack addition and time since addition $\left(\mathrm{F}_{2,21}=74.58, \mathrm{p}<0.001\right)$. Mean numbers of species $\mathrm{m}^{-2}$ prior to wrack addition $(8.1 ; \pm 1 \mathrm{SE}$ ranged from 7.1 to 9.1$)$ decreased one month later $(2.9$; $\pm 1 \mathrm{SE}$ ranged from 2.5 to 3.3 ), and numbers remained similar after 12 months (3.2; \pm 1 SE ranged from 2.6 to 3.8). Differences relative to pretreatment numbers were significant both one $\left(\mathrm{t}_{1,22}=15.8 ; \mathrm{p}<0.001\right)$ and 12 months after addition $\left(t_{1,22}=6.46 ; \mathrm{p}<0.001\right)$. In contrast, mean numbers of species $\mathrm{m}^{-2}$, which ranged from 8.8 to 11.2 in plots with wrack not added, did not change greatly (1 month $\mathrm{t}_{1,22}=-1.7 ; \mathrm{p}=0.530 ; 12$ month $\left.\mathrm{t}_{1,22}=-1.8 ; \mathrm{p}=0.486\right)$, producing the significant interaction between treatment nd time. As a result, plots with wrack added and without wrack differed both $1\left(\mathrm{t}_{1,20.6}=-10.11 ; \mathrm{p}<0.001\right)$ and 12 months $\left(\mathrm{t}_{1,18.6}=-6.83 ; \mathrm{p}<0.001\right)$ after treatment (Fig 3b).

Effects of wrack removal on numbers of species varied among life forms. Increases of 4-5 species of graminoids and forbs, on average, occurred by one year after removal of wrack (Fig. 4). The effects of wrack removal, time since removal and the interaction between removal and time were all highly significant for graminoids and forbs (Table 1).

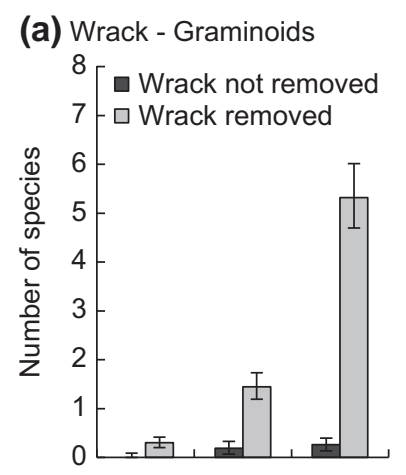

(e) Non-wrack - Graminoids

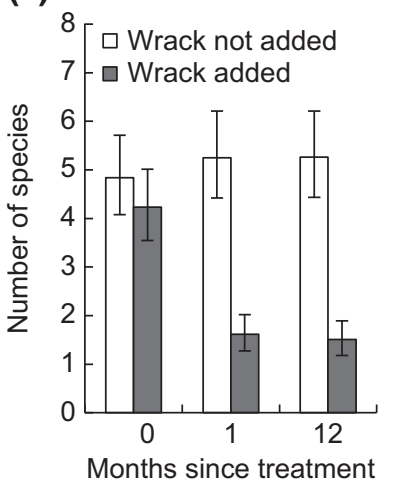

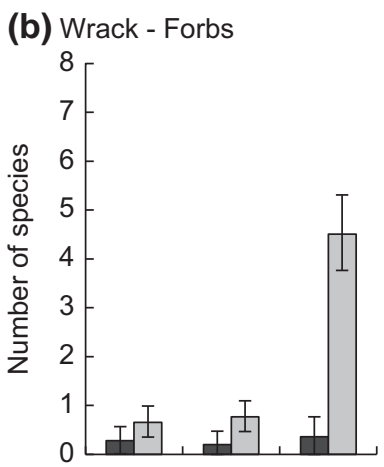

(f) Non-wrack - Forbs

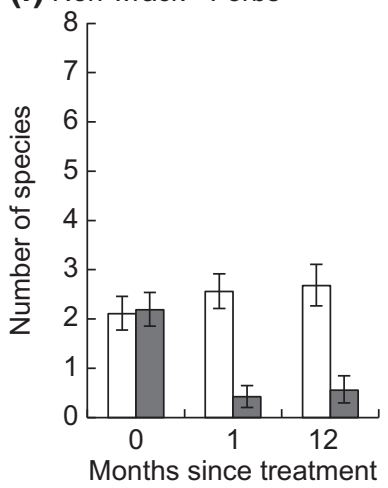

(c) Wrack - Shrubs

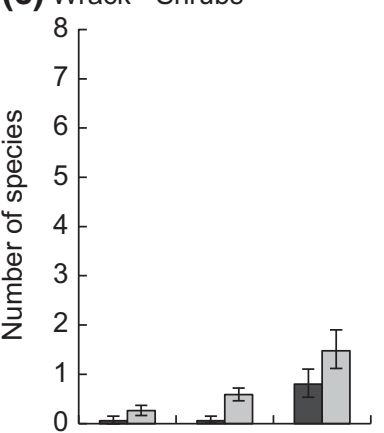

(g) Non-wrack - Shrubs

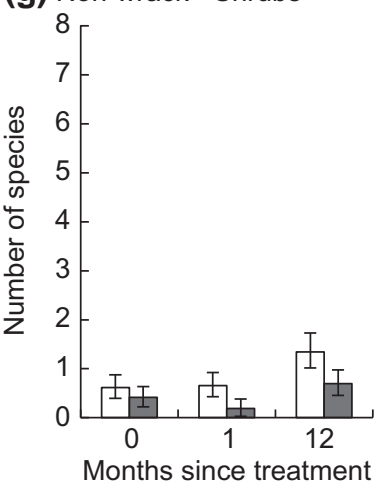

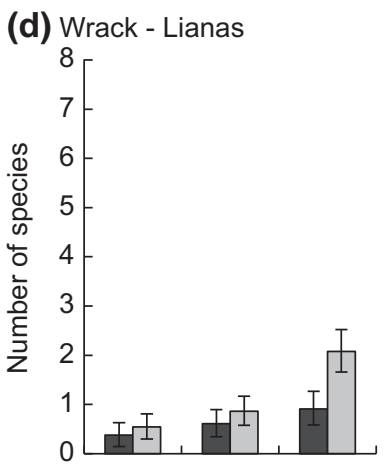

(h) Non-wrack - Lianas

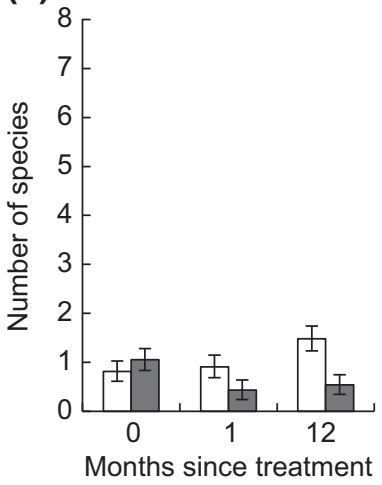

Figure 4. Numbers of species of different life forms prior to, and 1 and 12 months after treatment. Panels (a-d): wrack present at onset, then removed or not removed at time 0; $(\mathrm{e}-\mathrm{h})$ : wrack not present at onset, then added or not added at time 0 . Values are back-transformed means; vertical bars denote standard errors. 
Table 1. ANOVA of different life forms in wrack removal and wrack addition experiments. F values (F), numerator and denominator degrees of freedom (DF) calculated using Kenward-Roger approximations, and probabilities ( $\mathrm{p}$ ) are presented for treatment, time, and treatment $\mathrm{x}$ time interactions.

\begin{tabular}{|c|c|c|c|c|c|c|c|c|c|}
\hline \multirow[b]{3}{*}{ Life form } & \multicolumn{9}{|c|}{ Wrack plots } \\
\hline & \multicolumn{3}{|c|}{ Wrack removal } & \multicolumn{3}{|c|}{ Time } & \multicolumn{3}{|c|}{ Wrack removal $\times$ Time } \\
\hline & $\mathrm{F}$ & DF & $\mathrm{p}$ & $\mathrm{F}$ & DF & $\mathrm{p}$ & $\mathrm{F}$ & DF & $\mathrm{p}$ \\
\hline Graminoids & 61.86 & 1,22 & $<0.001$ & 50.92 & 2,21 & $<0.001$ & 31.53 & 2,21 & $<0.001$ \\
\hline Forbs & 36.99 & 1,19 & $<0.001$ & 15.34 & 2,21 & $<0.001$ & 12.74 & 2,21 & $<0.001$ \\
\hline Shrubs & 7.15 & 1,22 & 0.014 & 18.55 & 2,21 & $<0.001$ & 1.74 & 2,21 & 0.200 \\
\hline \multirow[t]{3}{*}{ Lianas } & 3.95 & $1,2.15$ & 0.176 & 10.41 & 2,21 & $<0.001$ & 2.25 & 2,21 & 0.130 \\
\hline & \multicolumn{9}{|c|}{ Non-wrack plots } \\
\hline & \multicolumn{3}{|c|}{ Wrack addition } & \multicolumn{3}{|c|}{ Time } & \multicolumn{3}{|c|}{ Wrack addition $\times$ Time } \\
\hline Life form & $\mathrm{F}$ & DF & $\mathrm{p}$ & $\mathrm{F}$ & DF & $\mathrm{p}$ & $\mathrm{F}$ & DF & $\mathrm{p}$ \\
\hline Graminoids & 51.9 & $1,20.4$ & $<0.001$ & 40.79 & 2,21 & $<0.001$ & 60.4 & 2,21 & $<0.001$ \\
\hline Forbs & 15.57 & 1,22 & $<0.001$ & 8.37 & 2,21 & 0.002 & 21.43 & 2,21 & $<0.001$ \\
\hline Shrubs & 2.69 & $1,20.5$ & 0.116 & 6.4 & 2,21 & 0.007 & 2.23 & 2,21 & 0.132 \\
\hline Lianas & 2.3 & 1,22 & 0.143 & 4.91 & 2,21 & 0.018 & 9.11 & 2,21 & 0.001 \\
\hline
\end{tabular}

On average, one year after treatments, as many graminoids, and more forbs were present in wrack removal plots as in non-wrack plots where no wrack was added (Fig. 4). Field observations indicated that these colonists originated from germination of seeds in the soil or at the surface beneath the wrack, rather than from clonal in-growth from pine savanna groundcover. Smaller increases occurred in species richness of shrubs and lianas after removal of wrack. In general, only 1-2 species of these life forms were present after one year. Effects of wrack removal on shrubs and lianas were significant only for shrubs, and interactions were not significant (Table 1).

Addition of wrack to areas without wrack caused numbers of species of some life forms to decline more than others. Numbers of graminoids and forbs were reduced by $>50 \%$ one year after wrack was added (Fig. 4). The effects of wrack addition, time since wrack addition and the interaction between wrack addition and time were all highly significant for graminoids and forbs (Table 1). Field observations indicated decreases in numbers were most pronounced for graminoids and forbs with a rosette growth form. The two dominant graminoids, Spartina patens and Panicum virgatum, survived in all plots; one year after wrack addition, some culms of these species had extended through the wrack. The density of culms one year after burial was a higher proportion of the original culm density for $P$. virgatum $(74 \pm 10 \%)$ than $S$. patens $(31 \pm 12 \%)$. Effects of wrack addition on shrubs and lianas were much less pronounced (Fig. 4). The effects of wrack addition were not significant for shrubs or lianas, and the interaction between wrack addition and time was not significant for shrubs (Table 1).

Species composition differed in experimental plots after onset of the field experiments. After one month (in July 2008), only a small proportion $(12.8 \pm 2.3 \%)$ of species in surrounding pine savanna also occurred in plots from which the wrack had been removed. About one species, on average, was shared between plots where wrack was present and then removed and plots where wrack was absent and not added. These were mostly rhizomatous or stoloniferous species that colonized via clonal growth from surrounding pine savanna. In addition, a few clonal sprouts of larger shrubs persisted through burial during Katrina and subsequent removal of wrack. Nonetheless, over half the species that colonized when wrack was removed did not occur aboveground in surrounding pine savanna. Furthermore, species that survived when wrack was added to plots also tended not to be those that colonized plots from which wrack was removed.

One year after treatment, species composition differed considerably among plots with wrack and from which wrack was removed and among plots without wrack and to which wrack was added. Three-dimensional NMS ordination (badness-of-fit $=0.14$ ) indicated substantial separation of plots with wrack and plots from which wrack had been removed along Axis 2 (Fig. 5a). In addition, plots from which wrack was removed tended to be more clumped along all axes than plots from which wrack had not been removed (Fig. 5a). Three-dimensional NMS ordination (badness-of-fit $=0.13$ ) also indicated substantial separation of plots without wrack and plots to which wrack had been added along Axis 1 (Fig. 5b). In addition, plots to which wrack was added tended to be slightly more clumped than plots without wrack (Fig. 5b).

Species composition remained different in areas with and without wrack one year after initiation of treatments. On average, $44.0 \pm 16.7 \%$ of the species in surrounding pine savanna plots had colonized at least one plot from which wrack had been removed. Nonetheless, more than half of the species that colonized when wrack was removed did not occur in any plot in surrounding pine savanna, and searches typically resulted in these species not being detected in surrounding pine savanna. Moreover, dominant graminoids (S. patens, P. virgatum) were not components of the groundcover vegetation in any plots from which wrack was removed.

One year after experiments were initiated, species tended not to be the same in plots to which wrack was added and plots where wrack had been removed. The proportion of species in wrack-added plots that were also present in wrack-removed plots increased from $7.6 \pm 1.3 \%$ in 2008 to $26.6 \pm 1.3 \%$ in 2009 . Thus, even one year later, many 
(a) Wrack

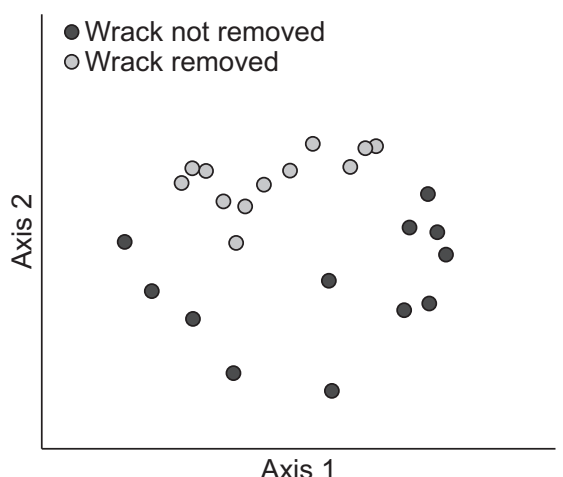

(b) Non-wrack

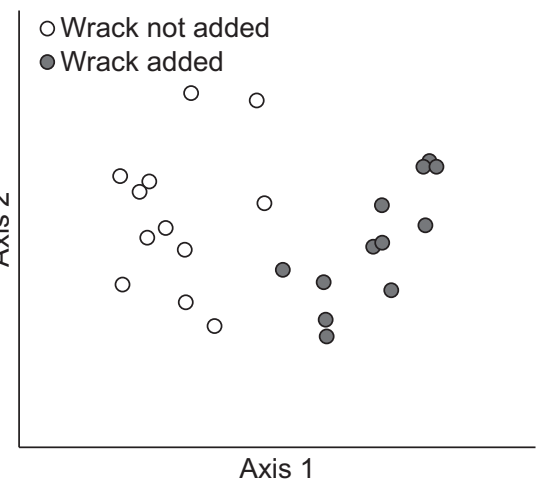

Figure 5. NMS ordinations depicting one-year post-treatment species assemblages. (a) Plots starting with wrack. Dark circles denote wrack not removed; lighter circles denote wrack removed. (b) Plots starting without wrack. Dark circles denote wrack added; open circles denote no wrack added. Axes 1 and 2 only of the three-dimensional ordinal space are shown for clarity.

species in wrack-removed plots were not species whose aboveground structures were capable of surviving burial by wrack. Moreover, by 2009, clonal shoots of the dominant graminoids (S. patens, P. virgatum) had grown through the wrack and were abundant in the groundcover vegetation of wrack-added plots, but did not occur in the groundcover of wrack-removed plots.

\section{Discussion}

\section{Wrack disturbance produces a range of effects on coastal savannas}

Our study explored effects of large amounts of wrack deposited by Hurricane Katrina storm surge in coastal pine savanna along the northern coast of the Gulf of Mexico. The wrack buried groundcover vegetation in sizable bands, leaving few aboveground legacies. Only trees and larger shrubs tended to survive burial by wrack deposits generated by major hurricanes, as also noted by Tate and Battaglia (2013). Post-hurricane savanna landscapes thus included catastrophically-disturbed patches (sensu Sousa 1984, Baldwin and Mendelssohn 1998, Platt and Connell 2003), interspersed with areas having much less disturbance.
Effects of major hurricane wrack deposits resemble some effects of tidal wrack deposits in coastal ecosystems. Tide-deposited wrack has been shown to affect salt marshes in ways that vary from little or no damage to removal of all species (Bertness and Ellison 1987, Shumway and Bertness 1994, Valiela and Rietsma 1995, Tolley and Christian 1999). One experimental study (Brewer et al. 1998) examined short-term effects of tide-deposited wrack in marshes at different elevations along a New England coastline. Where competitively dominant graminoids were killed by burial beneath wrack, competitively inferior fugitive species increased where wrack had been present (also see Bertness and Ellison 1987, Hartman 1988, Pennings and Richards 1998). Wrack thus has been hypothesized to open local patches of space that are transiently occupied by fugitive species, increasing heterogeneity and biodiversity in coastal landscapes (Brewer et al. 1998). Such effects of wrack appear to be dependent on the extent of deposits. Hartman (1988) suggested that most open patches in coastal salt marshes, such as those caused by tidal deposition of wrack, are small enough to be colonized by clonal growth of surrounding dominant graminoids. These studies suggest that wrack deposits constitute sizedependent, transient disturbances of coastal marshes; our study broadens this concept to include intense disturbances with long-lasting effects that cause transitions to alternate states.

Hurricane Katrina wrack deposits differed from tidal wrack in several major ways. Hurricane wrack, deposited upslope from tidal influence, settled into compact 'blankets' that decomposed slowly. After 3-5 yr, almost no plants had survived or colonized wrack deposits, except in small openings (e.g. tree/shrub wrack shadows). Graminoids dominant in surrounding groundcover invaded hurricane wrack patches only along the edges (cf. Bertness and Ellison 1987, Hartman 1988). Like some other hurricane effects (e.g. saltwater intrusion; Flynn et al. 1995), wrack disturbance may result in likelihoods of shifts to alternate states that increase with distance of wrack patches from the waterfront. Effects of wrack burial also may have been accentuated by seasonal timing of hurricanes; wrack tends to be deposited in late summer and fall, when plants are not likely to regrow through wrack before it compacts and settles.

Extended presence of wrack increases opportunities for interactions with secondary disturbances. Hurricanes are recurrent disturbances; regions like the Gulf of Mexico have return intervals of less than a decade (Doyle 2009). Thus, a subsequent hurricane that redistributes existing wrack has a high likelihood of suddenly opening areas buried in a prior hurricane, as well as burying vegetation in areas not previously disturbed. The effects of successive hurricanes should not, however, be considered as replicated disturbances. Our experimental redistribution of wrack from Hurricane Katrina produced effects different than those observed after the initial hurricane. After redeposition, vegetation was depressed, but about half the species, including dominant graminoids, recovered. We propose that minimal storm surges (from low-intensity hurricanes or those some distance from the site) should produce smaller wrack deposits; resistant plant species (sensu Boucher et al. 1994, Bellingham et al. 1995, Batista and 
Platt 2003) capable of growing through wrack should survive burial (also see Tate and Battaglia 2013). Pennings and Richards (1998) also noted regrowth through thin wrack deposits in tidal systems. Based on our study, we propose that species most resistant to burial should be those that produce one of two types of aboveground structures: stiff stems not as likely to be buried (e.g. shrubs, some forbs), or long, flexible culms or stolons that regrow by snaking through non-compacted wrack (e.g. flexible grass culms, lianas). Non-resistant or susceptible species, such as those with rosette growth forms, are unlikely to survive wrack burial.

Dominant savanna graminoids were somewhat resistant to burial by wrack. Some culms of Spartina patens and Panicum virgatum grew through our experimental wrack deposits and were present as sparse culms in plots. In the fall of 2008 wrack was deposited at GBNERR during storm surges of hurricanes (Gustav, Ike) crossing the Gulf of Mexico in September 2008 (also see Tate and Battaglia 2013). These less intense storm surges deposited wrack about $50 \mathrm{~cm}$ deep in areas exposed to tidal influence. In the spring of 2009, some buried ramets of dominant graminoids regrew through non-compacted wrack deposits. Our experimental data, coupled with field observations, suggest that dominant graminoids, while resistant, are negatively affected by small amounts of wrack. Effects of such wrack appear greater on growth forms (sensu Lovett-Doust 1981, Sackville-Hamilton et al. 1987) that are phalanx-like (e.g. S. patens) compared to those that are more guerrilla-like (e.g. P. virgatum). We anticipate that $P$. virgatum may increase in local relative abundance in savanna affected by wrack deposits, but be more persistent over time than Distichlis spicata in northern salt marshes (Brewer et al. 1998). Similar ranges in survival patterns have been noted for other largescale disturbances, such as tephra burial during volcanic eruptions (Tsuyuzaki 1989, del Moral and Grishin 1999).

We conclude that wrack transported by hurricane storm surges can be a major disturbance of coastal savanna groundcover. We propose that future studies of effects of wrack on coastal vegetation consider the following four conditions: 1) nature of wrack deposits (e.g. size of patch, amount deposited, and structural composition), 2) location (e.g. elevation above sea level and thus whether tides influence wrack deposits), 3) environmental conditions associated with deposition (e.g. salinity, continuity of cover, and obstacles that generate wrack shadows) and decomposition (e.g. nutrient and moisture content, and post-deposition packing of debris), and 4) seasonal timing of deposition of wrack. Variation in abiotic conditions associated with wrack disturbance should influence the nature and extent of changes in plant communities (also see Houle 2005). These characteristics of wrack disturbance should differentially affect resident species (Platt and Connell 2003), potentially producing effects from removal of all groundcover species in localized patches to differential persistence and slow to rapid recovery.

\section{Wrack disturbance can result in an alternate state of coastal savannas}

Wrack deposited by Hurricane Katrina produced extreme effects: species present at the time of disturbance did not recover. If competitively superior late species on a site do not survive disturbance, competitively inferior early species may, if they colonize the site, survive until late species recolonize and reoccupy the site (Platt and Connell 2003). Many groundcover species not present aboveground in undisturbed savanna responded rapidly following removal of Hurricane Katrina wrack. Post-disturbance assemblages of such early species are often designated 'weed patches' or 'early successional communities' rather than alternate states to pre-disturbance communities. We propose that extreme effects of wrack burial during Katrina set the stage for shifts, once wrack was removed, to an alternate state comprised of species whose life histories involve brief periods aboveground, and survival belowground between disturbances. Seeds of some of these species germinated within a month of wrack removal, and seeds of many more species germinated the following spring. Presumably, sufficient time passed between deposition and subsequent removal of wrack that some effects of hurricane storm surge such as salinity were diminished (also see Middleton 2009). Most plants that responded to wrack removal were associated with the soil seed bank, and were annuals or short-lived herbaceous perennials.

A limited number of seeds that germinated when wrack was removed were associated with a layer of decomposing duff beneath remaining debris. These seeds typically did not occur in surrounding coastal pine savanna; most likely they were carried into pine savanna along with the wrack from brackish marshes. These plants (e.g. Echinochloa walteri, Hibiscus moscheutos, Kosteletzkya virginica, Sesbania vesicaria) flower and set seed in late summer, producing seeds that are mature at the time of hurricane landfalls (unpubl.). The buoyant seeds (Poljakoff-Mayber et al. 1992) could be dispersed by wrack (Minchinton 2006 and references therein). These seeds often germinated shortly after remaining wrack was removed; plants grew rapidly, flowered, and produced seeds either the same or subsequent year.

Most species that germinated when wrack was removed were in the soil beneath wrack. These species, indigenous to coastal pine savannas or adjacent marshes, tended not to be present aboveground in coastal pine savanna. Baskin and Baskin (2001) summarize studies indicating that many plant species in wetland habitats have seeds with physiological dormancy, and that these seeds tend to germinate when salinities and water levels are lowered. We noted that exposure to light or warm temperatures following removal of wrack also appeared to be a germination cue for some of these species.

Some species that germinated when wrack was removed exhibited ephemeral post-disturbance responses. A few species (e.g. Echinochloa walteri, Erechtites hieracifolium, Panicum verrucosum) germinated within weeks, grew rapidly, flowered and set seed before the next growing season. They then disappeared aboveground, but seeds presumably were deposited in the substrate. Such ephemeral species, or their close relatives, have been noted to respond rapidly to largescale disturbance in wetland and savanna ecosystems (Kirkman and Sharitz 1994, Baskin et al. 1999). Other annual species germinated the spring after wrack was removed, then grew to maturity and set seed the same year. These species then disappeared aboveground, based on field 
observations in 2010. Some were fresh-marsh annuals (e.g. Bidens coronata, Pluchea rosea, Ptilimnium capillaceum). Others were typical of coastal savannas (e.g. Sabatia stellaris, Setaria parviflora). Annual plant species comprised about $15 \%$ of the species recorded in our study, greatly outnumbering similar ephemeral species in more northern coastal wetlands.

Colonists of sites where wrack was removed also included a number of wetland species that persist on sites for more than one year after germination. Most of these species, both graminoids (e.g. Andropogon, Carex, Dichanthelium, Sacciolepis) and forbs (e.g. Linum, Ludwigia, Neptunia, Polygonum, Proserpinaca, Ruellia, Samolus), were not present aboveground in coastal savanna without wrack, and so we inferred that they were shortlived perennials. These species germinated the spring after wrack was removed and grew rapidly, often flowering that year. Observations indicated that these species typically were present at least until 2012. These perennial species comprised $50 \%$ of the coastal savanna flora recorded in our study. Thus, $65 \%$ of the total flora (Supplementary material Appendix 1) in all plots consisted of resilient annual and short-lived perennial 'super-early' species not typically found in undisturbed coastal pine savanna. Similar life histories (although smaller components of local species pools) have been noted in other herbaceous wetlands (Hartman 1988, Gerritson and Greening 1989, Kirkman and Sharitz 1994, Brewer et al. 1998, Pennings and Richards 1998, Middleton 2009). Nonetheless, some fresh-water marshes may have many dormant species also (Peterson and Baldwin 2004).

Assemblages of plants that formed after wrack removal did not resemble assemblages in surrounding coastal pine savanna. Most initial colonists were not present in undisturbed pine savanna groundcover, and if present, they were overwhelmingly under-represented. Plant species often have been designated fugitives if they respond to opening of space, but do not persist aboveground between disturbances (Platt 1975, Brewer et al. 1998). We emphasize that more than half of the coastal savanna species pool actually does persist on site during intervals between disturbances, just belowground (cf. Platt and Connell 2003; also see Baskin and Baskin 2001). Because they do not go extinct locally (the sense of 'fugitive' used by Hutchinson 1951, also Platt 1975), post-wrack colonists should be more appropriately considered resilient (sensu Boucher et al. 1994, Bellingham et al. 1995, Batista and Platt 2003) rather than fugitive species (cf. Bertness et al. 1992, Brewer et al. 1998). Rapid response to disturbance and return of offspring to a seed bank has been suggested as an evolutionary response to recurrent disturbances that provides opportunity for growth and seed production in physically demanding environments without necessitating dispersal to new sites each generation (Sousa 1984, Bertness et al. 1992, Grime and Hillier 2000, Keddy 2010).

We propose that habitats with a history of frequent large-scale disturbances may be characterized by high biodiversity alternate states. As disturbances recurrently open sites to invasion, numbers of 'super-early' species that spend brief periods of time aboveground and long periods belowground should increase. Therefore, aboveground assemblages may obscure a diversity of species capable of rapid, but ephemeral, post-disturbance responses. We propose that these species that spend most of their time belowground should not be considered as transient augmentation of aboveground diversity, but as comprising alternate states. Such alternate states may appropriately characterize savannas. In recent years, hardwood forest has been proposed as an alternate state to savanna, one in which the trigger for state shifts in trees is a change in fire return interval (Peterson 2002, Beckage et al. 2009). Likewise, 'super-early' assemblages of coastal savanna groundcover constitute an alternate state to graminoiddominated groundcover, and the trigger for state shifts is deposition of large amounts of wrack by hurricanes.

Wrack-generated herbaceous assemblages only superficially resemble surrounding coastal savanna. Local variation in soil seed banks (Baskin and Baskin 2001) and responsiveness to different post-disturbance conditions (Ungar 1987, Middleton 2009), coupled with variation in dispersal via tides and wrack (Huiskes et al. 1995, Chang et al. 2008), should generate variation in belowground propagules (sensu Levine and Murrell 2003) and hence in composition and aspect dominance of local post-disturbance assemblages. Such heterogeneity contrasts markedly with the similarity of aspect dominance by dominant graminoids in the surrounding groundcover not influenced by wrack deposits, magnifying local variation in the post-disturbance state. In addition, the dynamics of belowground seed populations, as well as the timing of hurricanes relative to seed production of wrack-transported species, should result in temporal variation in the immigration-driven accumulation of biodiversity, and thus the nature of alternate states that result from wrack disturbance (also see Brown and Peet 2003). The dynamic relationship between resistance and resilience of species present above and below ground at the time of disturbance, immigration of new species from elsewhere, and the potential influence of local environmental conditions underscore the potential for disturbance-driven biodiversity in these alternate states (cf. Folke et al. 2001).

Are such states persistent or transient? Our study focused on initial formation of herb-dominated groundcover as alternates states to coastal pine savanna graminoiddominated groundcover. We did not explore longerterm changes, although our experimental study suggests that hysteresis might result if survival of graminoids were dependent on genet size. We anticipate that, in the absence of subsequent disturbance, changes from herb- to graminoid-dominated states might ultimately depend on colonization ability and competitive relationships between dominant graminoids and 'early' species, as hypothesized by Brewer et al. (1998). Post-Katrina plant communities that formed after dense compacted wrack deposits were removed did not contain Spartina patens and Panicum virgatum. These species do not have dormant seeds in the soil, and seeds are dispersed after the time at which hurricanes are most likely to make landfall. Further, production of viable seeds (especially $S$. patens) typically is low, and clonal spread into unoccupied areas occurs slowly. As a result, wrack-generated alternate states, especially in larger patches, are likely to persist for a number of years, although 
without subsequent hurricanes, dominant graminoids might well eventually become reestablished (also see Holt et al. 1995). Such limits to reinvasion by dominant savanna species could provide opportunities for super-early species to colonize groundcover opened by wrack disturbance and form loosely-organized diverse assemblages structured by immigration-dependent dynamics and comprised of different species over space and time.

Our study suggests that coastal savanna groundcover should consist of a heterogeneous mixture of states. Frequent deposition of variable amounts of wrack in different locations and at different times of the year, coupled with secondary disturbances that change locations of wrack deposits, should result in changing mosaics of wrack disturbance in coastal savanna landscapes. A range of postdisturbance community states, from differential survival of savanna groundcover species to extreme conditions of local patches with no surviving species that shift to alternate herb-dominated states, should be expected in coastal savanna landscapes that experience frequent hurricanes. If landfalls of intense hurricanes in the Gulf of Mexico increase in frequency as a result of climate change, as predicted (Emanuel 2013, Villarini and Vecchi 2013), then groundcover comprising coastal savannas should become even more heterogeneous, with increased occurrence of alternate states resulting from extensive wrack deposits.

Acknowledgements - We thank Skyla Duncan for her assistance with the study. Logistic support was provided by the Grand Bay National Estuarine Research Reserve, especially Dave Ruple, Manager, and Mark Woodrey, Research Coordinator. Parts of this study were conducted under the auspices of the Louisiana State Univ. Summer Research Program in 2008 and 2009. Work was supported by the Undergraduate Research Opportunity Program of the Louisiana Sea Grant College Program (awarded to DJ), National Center for Research Resources of the National Institutes of Health (P20RR016456), the National Science Foundation (SGER 0612477, WJP, PI), the Dept of Energy National Inst. for Climate Change Research (NICCR, WJP, co PI), and a Coastal Restoration and Enhancement through Science and Technology Grant (10-2 \#115804124, WJP, PI).

\section{References}

Baldwin, A. H. and Mendelssohn, I. A. 1998. Response of two oligohaline marsh communities to lethal and nonlethal disturbance. - Oecologia 116: 543-555.

Baskin, C. C. and Baskin, J. M. 2001. Seeds: ecology, biogeography, and evolution of dormancy and germination. - Academic Press.

Baskin, C. C. et al. 1999. Seed dormancy in the wetland winter annual Ptilimnium nuttallii (Apiaceae). - Wetlands 19: 359-364.

Batista, W. B. and Platt, W. J. 2003. Tree population response to hurricane disturbance: syndromes in a southeastern United States old-growth forest. - J. Ecol. 91: 197-212.

Beckage, B. et al. 2009. Vegetation, fire and feedbacks: a disturbancemediated model of savannas. - Am. Nat. 174: 805-818.

Bellingham, P. J. et al. 1995. Damage and responsiveness of Jamaican montane tree species after disturbance by a hurricane. - Ecology 76: 2562-2580.

Bertness, M. D. and Ellison, A. M. 1987. Determinants of pattern in a New England salt marsh plant community. - Ecol. Monogr. 57: 29-147.
Bertness, M. D. et al. 1992. Salt tolerances and the distribution of fugitive salt marsh plants. - Ecology 73: 1842-1851.

Boucher, D. H. et al. 1994. Resistance and resilience in a directly regenerating rainforest: Nicaraguan trees of the Vochysiaceae after Hurricane Joan. - For. Ecol. Manage. 68: 127-136.

Brewer, J. S. et al. 1998. Interactive effects of elevation and burial with wrack on plant community structure in some Rhode Island salt marshes. - J. Ecol. 86: 125-136.

Brown, R. L. and Peet, R. K. 2003. Diversity and invasibility of southern Appalachian plant communities. - Ecology 84: 32-39.

Bush, D. M. et al. 1996. Soundside impacts of a northward tracking tropical cyclone: Hurricane Emily (31AUG93), Cape Hatteras area, North Carolina. - J. Coastal Res. 12: 229-239.

Chang, E. R. et al. 2008. To move or not to move: determinants of seed retention in a tidal marsh. - Funct. Ecol. 22: 720-727.

Davis, S. E. et al. 2004. Importance of storm events in controlling ecosystem structure and function in a Florida gulf coast estuary. - J. Coastal Res. 20: 1198-1208.

del Moral, R. and Grishin, S. Y. 1999. Volcanic disturbances and ecosystem recovery. - In: Walker, L. R. (ed.), Ecosystems of disturbed ground. Elsevier, pp. 137-160.

del Moral, R. and Lacher, I. L. 2005. Vegetation patterns 25 years after the eruption of mount St. Helens, Washington, USA. - Am. J. Bot. 92: 1948-1956.

Doyle, T. W. 2009. Hurricane frequency and landfall distribution for coastal wetlands of the Gulf coast, USA. - Wetlands 29: 35-43.

Emanuel, K. 2005. Divine wind: the history and science of hurricanes. - Oxford Univ. Press.

Emanuel, K. 2013. Downscaling CMIP5 climate models shows increased tropical cyclone activity over the 21 st century. - Proc. Natl Acad. Sci. USA 110: doi: 10.1073/pnas.1301293110

FEMA 2005. Hurricane Katrina surge inundation and advisory base flood elevation maps, Dec. 2005-Jan. 2006. - <www. fema.gov/hazard/flood/recoverydata/katrina/katrina_ms_ jackson.shtm $>$.

Flynn, K. M. et al. 1995. Recovery of freshwater marsh vegetation after a saltwater intrusion event. - Oecologia 103: 63-72.

Folke, C. et al. 2001. Regime shifts, resilience, and biodiversity in ecosystem management. - Annu. Rev. Ecol. Syst. 35: 557-81.

Fritz, H. M. et al. 2008. Hurricane Katrina storm surge reconnaissance. - J. Geotech. Geoenviron. Eng. 134: 644-656.

Gerritson, J. and Greening, H. S. 1989. Marsh seed banks of the Okefenokee Swamp: effects of hydrologic regime and nutrients. - Ecology 70: 750-763.

Grime, J. P. and Hillier, S. H. 2000. The contribution of seedling regeneration to the structure and dynamics of plant communities, ecosystems, and larger units of the landscape. - In: Fenner, M. (ed.), Seeds: the ecology of regeneration in plant communities. CABI Publishing, pp. 361-374.

Guntenspergen, G. R. et al. 1995. Disturbance and recovery of the Louisiana coastal marsh landscape from the impacts of Hurricane Andrew. - J. Coastal Res. SI 21: 324-339.

Hackney, C. T. and Bishop, T. D. 1979. The effect of Hurricane Bob (July 11, 1979) on the St. Louis tidal marshes: transport and relocation of debris. - Technical Report, MississippiAlabama Sea Grant Consortium Publication No. MASGP-79015, Ocean Springs, MS, <www.masgc.org/pdf/masgp/79-015. pdf $>$.

Harper, R. L. 1914. A superficial study of the pine-barren vegetation of Mississippi. - Bull. Torrey Bot. Club 41: 551-567.

Hartman, J. M. 1988. Recolonization of small disturbance patches in a New England salt marsh. - Am. J. Bot. 75: 1625-1631.

Hilbert, K. W. 2006. Land cover change within the Grand Bay National Estuarine Research Reserve: 1974-2001. - J. Coastal Res. 22: 1552-1557. 
Holt, R. D. et al. 1995. Vegetation dynamics in an experimentally fragmented landscape. - Ecology 76: 1610-1624.

Houle, G. 2005. A multivariate analysis of fine-scale species density in the plant communities of a saltwater lagoon - the importance of disturbance intensity. - Oikos 111: 465-472.

Huiskes, A. H. L. et al. 1995. Seed dispersal of halophytes in tidal salt marshes. - J. Ecol. 83: 559-567.

Hutchinson, G. E. 1951. Copepodology for the ornithologist. - Ecology 32: 571-577.

Keddy, P. A. 2010. Wetland ecology: principles and conservation. - Cambridge Univ. Press.

Kenward, M. G. and Roger, J. H. 2009. An improved approximation to the precision of fixed effects from restricted maximum likelihood. - Comput. Stat. Data Analysis 53: 2583-2595.

Kirkman, I. K. and Sharitz, R. R. 1994. Vegetation disturbance and maintenance of diversity in intermittently flooded Carolina bays in South Carolina. - Ecol. Appl. 4: 177-188.

Knabb, R. D. et al. 2005. Tropical cyclone report, Hurricane Katrina 23-30, August 2005, National Hurricane Center, 20 Dec. 2005. - National Hurricane Center, National Oceanic and Atmospheric Administration, Miami, FL, <www.nhc. noaa.gov/pdf/TCR-AL122005_Katrina.pdf>.

Lam, N. S.-N. et al. 2011. Impacts of hurricanes on Gulf coast ecosystems: a remote sensing study of land cover change in Weeks Bay, Alabama. - J. Coastal Res. SI 64: 1707-1711.

Levine, J. M. and Murrell, D. J. 2003. The community-level consequences of seed dispersal patterns. - Annu. Rev. Ecol. Evol. Syst. 34: 549-574.

Lovett-Doust, L. 1981. Population dynamics and local specialization in a clonal plant (Ranunculus repens). I. The dynamics of ramets in contrasting habitats. - J. Ecol. 69: 743-755.

Middleton, B. A. 2009. Regeneration of coastal marsh vegetation impacted by hurricanes Katrina and Rita. - Wetlands 29: 54-65.

Minchinton, T. E. 2006. Rafting on wrack as a mode of dispersal for plants in coastal marshes. - Aquat. Bot. 84: 372-376.

Pennings, S. C. and Richards, C. L. 1998. Effects of wrack burial in salt-stressed habitats: Batis maritima in a southwest Atlantic salt marsh. - Ecography 21: 630-638.

Peterson, G. D. 2002. Forest dynamics in the southeastern United States: managing multiple stable states. - In: Gunderson, L. H. and Pritchard Jr, L. (eds), Resilience and the behavior of large scale ecosystems. Island Press, pp. 227-246.

Peterson, J. E. and Baldwin, A. H. 2004. Variation in wetland seed banks across a tidal freshwater landscape. - Am. J. Bot. 91: 1251-1259.

Supplementary material (Appendix ECOG-00731 at $<$ www.ecography.org/readers/appendix $>$ ). Appendix 1.
Platt, W. J. 1975. The colonization and formation of equilibrium plant species associations on badger disturbances in a tallgrass prairie. - Ecol. Monogr. 45: 285-305.

Platt, W. J. and Connell, J. H. 2003. Natural disturbances and directional replacement of species. - Ecol. Monogr. 73: 507-522.

Poljakoff-Mayber, A. et al. 1992. Seeds of Kosteletzkya virginica (Malvaceae): their structure, germination, and salt tolerance. I. Seed structure and germination. - Am. J. Bot. 79: 249-256.

Rodgers, J. C. et al. 2009. The impact of Hurricane Katrina on the coastal vegetation of the Weeks Bay Reserve, Alabama from NDVI data. - Estuaries Coasts 32: 496-507.

Roman, C. T. et al. 1994. Hurricane Andrew's impact on freshwater resources. - Bioscience 44: 247-255.

Sackville-Hamilton, N. R. et al. 1987. Life-history concepts and the population biology of clonal organisms. - Proc. R. Soc. B 232: 35-57.

Scheffer, M. and Carpenter, S. R. 2003. Catastrophic regime shifts in ecosystems: linking theory to observation. - Trends Ecol. Evol. 18: 648-656.

Scheffer, M. et al. 2001. Catastrophic shifts in ecosystems. - Nature 413: 591-596.

Shumway, S. W. and Bertness, M. D. 1994. Patch size effects on marsh plant secondary succession mechanisms. - Ecology 75: $564-568$.

Sousa, W. P. 1984. The role of disturbance in natural communities. - Annu. Rev. Ecol. Syst. 15: 353-391.

Tate, A. S. and Battaglia, L. L. 2013. Community disassembly and reassembly following experimental storm surge and wrack application. - J. Veg. Sci. 24: 46-57.

Tolley, P. M. and Christian, R. R. 1999. Effects of increased inundation and wrack deposition on a high salt marsh plant community. - Estuaries 22: 944-954.

Tsuyuzaki, S. 1989. Analysis of revegetation dynamics on the volcano Usu, northern Japan, deforested by 1977-1978 eruptions. - Am. J. Bot. 76: 1468-1477.

Ungar, I. A. 1987. Population ecology of halophyte seeds. - Bot. Rev. 53: 301-334.

USDA, NRCS. 2013. The PLANTS database. - National Plant Data Team, Greensboro, NC 27401-4901 USA, <http:// plants.usda.gov>, accessed 21 September 2013.

Valiela, I. and Rietsma, C. S. 1995. Disturbance of salt marsh vegetation by wrack mats in Great Sippewissett marsh. - Oecologia 102: 106-112.

Villarini, G. and Vecchi, G. A. 2013. Projected increases in North Atlantic tropical cyclone intensity from CMIP5 models. - J. Clim. 26: 3231-3240.

Weakley, A. S. 2012. Flora of the southern and mid-Atlantic States. - UNC Herbarium, Chapel Hill, <www.herbarium.unc.edu/ flora.htm $>$. 